\title{
Patient satisfaction and associated factors among in-patients in Primary Hospitals of North Shoa Zone, Amhara Regional State, Ethiopia
}

\author{
Zenebe Wondimhunegn Weldearegay ${ }^{1}$, Sisay Shewasinad Yehualahet ${ }^{2}$, Shimelse Ololo Sinkie ${ }^{3}$, \\ Tilahun Fufa Debela ${ }^{4}$ \\ ${ }^{1}$ Debre Sina primary Hospital, Ethiopia \\ ${ }^{2}$ Nursing Department, Debre Berhan University, Ethiopia \\ ${ }^{3,4}$ Department of health policy and management, Jimma University, Ethiopia
}

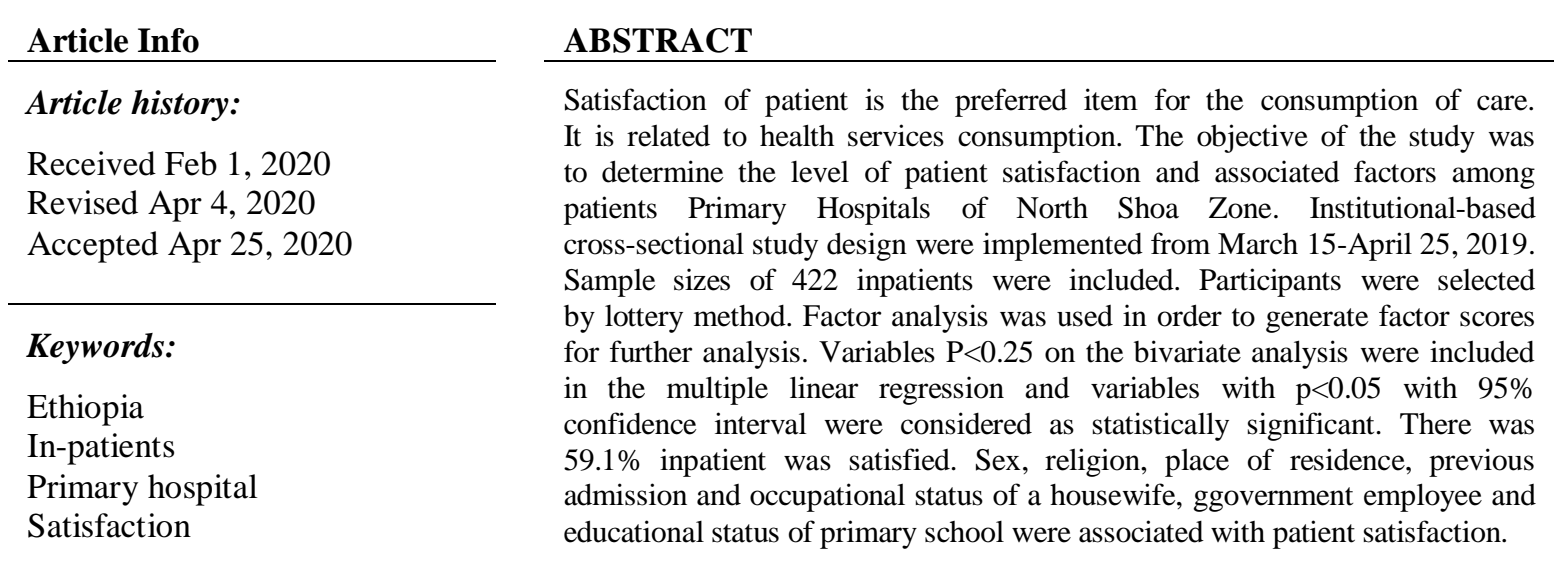

This is an open access article under the CC BY-SA license.

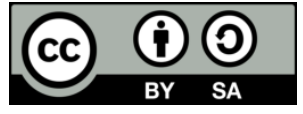

Corresponding Author:

Zenebe Wondimhunegn Weldearegay,

Debre Sina primary Hospital,

Ethiopia.

Email: zenewond8@gmail.com

\section{INTRODUCTION}

Patient satisfaction is defined as one of the desired outcomes of health care and it is directly related to the utilization of health services [1]. Clients have clear necessities for care while they carry on in hospital. though, not enough respond to desires if the patient has disappointment [2]. The world health description stress on health systems as a crucial component of their overall performance defining as the way the system responds to non-health aspects and whether meeting or not patient expectations [3]. Ethiopia health sector reform has been implemented since 2010 as part of the national effort of socio-economic civil service reform to the public sector through the application of Business Process Reengineering. The rationale on behalf of the healthiness segment is to create customer-focused organization [4]. The communication influenced patient satisfaction. When patient had good communication with health professional, patients are actively involved in the care plan [5].

Patient satisfaction with hospital care is significantly influenced by patient-provider interactions during the incident of care, the hospital physical environment, interpersonal skills in terms of good manners, value by health care providers, communication skills, clarification, and clear information, and technical skills such as clinical competency and hospital equipment [6]. Factors affecting patient satisfaction include 
accessibility of hospitals, surrounding environment, working hours, cleanliness, food services quality were considered [7]. Health association have to give continuous and success patient centered care [8]. Socio-demographic of the patient influence the hope of the care [9]. Age, gender, language, culture, education status, anxiety and previous hospitalization influence patient satisfaction [10]. Participants with tertiary education were dissatisfied when compared with illiterate and basic education [11]. Poor working conditions, heavy workloads, lack of participation in decision making, and limited opportunities for career mobility. Consequently, lack of resources, as well as professional, environmental and other restraints and limitations [12].

The study revealed a significant association among patient age and patient satisfaction [13]. A study done at a black lion hospital showed that 374 adult participants with a $100 \%$ response rate [14]. Language barrier were determining factor of patient satisfaction [15]. The patient unable to fully express their felling to the nurse were determining factors for patient [16]. Different studies have reported varying levels of inpatient satisfaction in different levels of hospitals in Ethiopia. A study conducted in Addis Ababa, $67 \%$ of patient were satisfied [17]. A study done at Jimma University Specialized Hospital $77.0 \%$ were satisfied [18]. Patient at Mozambique Hospital, 55\% patient were satisfied [19].

A study conducted in Amhara region satisfaction level were $22.0 \%$ to 50\% [20]. Study done at Tigray zonal hospitals satisfaction level was $43.60 \%$ [21]. A study done at Debre Markos hospital patient satisfaction was $56 \%$ [22]. To improve services quality, satisfying patients is the primary goal of the Ethiopian government's transformation agenda. Hospitals and health professionals [23, 24]. Higher levels of patient capacity building, promise to care and adherence to recommended management were associated with patient outcome [25]. The Federal Ministry of health in Ethiopia set 36 national key performance indicators (KPIs) reflecting processes and outcomes. The inpatient service KPI includes: admissions, mortality, surgical admission timeliness, bed occupancy, the average length of stay, pressure ulcer incidence, surgical site infection and completeness of inpatient medical records [26].

Lack of high-quality equipment exaggerated the provision of quality care [27]. A study in South Africa reported that, the highest waiting time was associated with patient dissatisfaction [28]. There were different factors that delay the health care provider to attain better health outcomes [29]. Male patient had higher satisfaction for health care services, others males were dissatisfied [30, 31]. It is necessary to assess patient satisfaction at the primary hospital levels. Most of the previous studies addressed on the nursing care aspect of the hospital service. But according to Ethiopian hospital service transformation guideline inpatient service patient satisfaction should be measure in terms of all available inpatient service provided in the hospital setting. For this reason; the objective of study to determine the level of patient satisfaction and identifying factors.

\section{RESEARCH METHOD}

The study was conducted among Primary Hospitals of North Shoa Zone. The study was conducted from March 15-April 25/2019. Cross-sectional study design was implemented. A single population proportion formula was used. The following assumptions were made, margin of error (d) 5\%, and using $95 \%$ confidence level, the proportion of inpatient satisfaction $(\mathrm{P}=50 \%), 10 \%$ non-responses with 422 participants. The sample was allocated to each hospital based on the size of admitted patients. Then the sample was distributed to three wards (medical, surgical and gynecological wards). Study participants were selected every two-interval during discharge time. The data was collected through face to face interview using structured questionnaires, the questionnaires were adopted from reviewed literature [32]. Data were coded and entered into Epi data version 3.1 and exported to SPSS version 21 for analysis.

Factor analysis was conducted. Factor scores were computed for the item identified to represent the satisfaction scale by varimax rotation. In this study, sampling adequacy was (KMO=0.964). A linear regression model was fitted to identify factors associated with patient satisfaction. Bivariate linear regression analysis was performed to examine the association between each independent variable with the dependent variable. All variables with $(\mathrm{p}<0.25)$ on the bivariate were included in the final multiple linear regression model to identify associated factors of patient satisfaction. Variables with $(\mathrm{p}<0.05)$, with the level of significance at $95 \%$ confidence interval and un-standardized $\beta$ coefficient was used for interpretation of significant association with patient satisfaction. The questionnaire was developed in English and translated into Amharic (local language) and back-translated into English to ensure its consistency by expertise. The reliability of the questioner checked and $\alpha$ was 0.965 . The pre-test was done in Kemise Primary Hospitals. 


\section{RESULTS AND DISCUSSION}

\subsection{Socio-demographic characteristics of respondents}

Among 422 participants, 418 respondents were voluntary to participate. The mean ages of the respondents were $32.38(\mathrm{SD} \pm 11.991)$ years and $105(25.1 \%)$ of them were between the age of 25-29 years. Two hundred sixty-four $(63.2 \%)$ were females. Half of the respondents $211(50.5 \%)$ were urban residents. Regarding educational status, $287(68.7 \%)$ respondents had a primary school and above educational level. It can be seen in Table 1.

Table 1. Socio-demographic characteristics respondent

\begin{tabular}{|c|c|c|c|}
\hline Variable & Category & Frequency $(n=418)$ & Percentage \\
\hline \multirow{7}{*}{ Age } & $15-19$ & 17 & 4.1 \\
\hline & $20-24$ & 89 & 21.3 \\
\hline & $25-29$ & 105 & 25.1 \\
\hline & $30-34$ & 67 & 16 \\
\hline & $35-39$ & 46 & 11 \\
\hline & $40-44$ & 34 & 8.1 \\
\hline & $45^{+}$ & 60 & 14.4 \\
\hline \multirow{3}{*}{ Sex } & Male & 154 & 36.8 \\
\hline & Female & 264 & 63.2 \\
\hline & Married & 321 & 76.8 \\
\hline \multirow{3}{*}{ Marital status } & Single & 76 & 18.2 \\
\hline & Divorced & 16 & 3.8 \\
\hline & Widowed & 5 & 1.2 \\
\hline \multirow{3}{*}{ Religion } & Orthodox & 343 & 82.1 \\
\hline & Muslim & 66 & 15.8 \\
\hline & Protestant & 9 & 2.2 \\
\hline \multirow{2}{*}{ Residence } & Urban & 211 & 50.5 \\
\hline & Rural & 207 & 49.5 \\
\hline \multirow{5}{*}{ Occupation } & Housewife & 127 & 30.4 \\
\hline & Farmer & 133 & 31.8 \\
\hline & Government employee & 71 & 17 \\
\hline & private Business & 20 & 4.8 \\
\hline & Other & 67 & 16 \\
\hline \multirow{6}{*}{ "Educational status } & No education & 131 & 31.3 \\
\hline & Primary school (1-8) & 115 & 27.5 \\
\hline & Secondary $(9-10)$ & 63 & 15.1 \\
\hline & Preparatory (11-12) & 14 & 3.3 \\
\hline & diploma & 57 & 13.6 \\
\hline & Degree & 38 & 9.1 \\
\hline Household & Mean $=1633.65$ & $<1633.65=258$ & 61.7 \\
\hline \multirow{2}{*}{ Income in Ethiopian Birr(monthly) } & $\mathrm{SD} \pm 2088.203$ & $\geq 1633.65=160$ & 38.3 \\
\hline & Free & 151 & 36.1 \\
\hline \multirow[t]{2}{*}{ Paying status } & Paying & 124 & 29.7 \\
\hline & CBHI & 143 & 34.2 \\
\hline \multirow[t]{2}{*}{ Family size } & $<=5$ & 338 & 80.9 \\
\hline & $>5$ & 80 & 19.1 \\
\hline
\end{tabular}

\subsection{Admission characteristics of respondents}

From the total 418 inpatient respondents, 357 (85.4\%) of them stayed less or equal to five days in the wards and more than half of therespondents $230(55 \%)$ were admitted for the first time. Most of the respondents $232(55.5 \%)$ were admitted at the medical ward and $153(36.6 \%)$ were at the gynecology ward.

\subsection{Hospital facility-related satisfaction}

From all respondents $270(64.6 \%)$ were fell comfort for examination rooms, $243(58.1 \%)$ were interested regarding to cleanliness of the wards that can be seen in Table 2.

\subsection{Service appropriateness related satisfaction}

Most of the respondents $289(71.5 \%)$ were satisfied with the diagnostic service. Likewise, high level of satisfaction was reported on the progress of the treatment $292(69.9 \%)$, by the availability of prescribed drugs $307(73.4 \%)$, by the payment condition 305 (73.0\%), and by access to laboratory and x-ray diagnosis were $295(70.5 \%)$.

Int. J. Public Health Sci, Vol. 9, No. 2, June 2020: 76 - 81 
Table 2. Satisfaction level with facilities

\begin{tabular}{|c|c|c|c|c|c|}
\hline Variable & $\begin{array}{c}\text { Strongly dissatisfied } \\
\mathrm{n}(\%)\end{array}$ & $\begin{array}{c}\text { Dissatisfied } \\
\mathrm{n}(\%)\end{array}$ & $\begin{array}{c}\text { Neutral } \\
\mathrm{n}(\%)\end{array}$ & $\begin{array}{l}\text { Satisfied } \\
\mathrm{n}(\%)\end{array}$ & $\begin{array}{c}\text { Strongly } \\
\text { satisfied } \\
\mathrm{n}(\%)\end{array}$ \\
\hline Availability of material example, wheelchair & $44(10.5)$ & $36(8.6)$ & $84(20.1)$ & $100(23.9)$ & $154(36.8)$ \\
\hline Cleanliness of the ward & $32(7.7)$ & $52(12.4)$ & $91(21.8)$ & $97(23.2)$ & $146(34.9)$ \\
\hline Adequacy of ward space & $32(7.7)$ & $36(8.6)$ & $92(22.0)$ & $108(25.8)$ & $150(35.9)$ \\
\hline Ward room light and ventilation & $28(6.7)$ & $33(7.9)$ & $72(17.2)$ & $120(28.7)$ & $165(39.5)$ \\
\hline Access to water & $49(11.7)$ & $72(17.2)$ & $86(20.6)$ & $103(24.6)$ & $108(25.8)$ \\
\hline Access to latrine & $34(8.1)$ & $69(66.2)$ & $115(27.5)$ & $105(25.1)$ & $95(22.7)$ \\
\hline Access to hand washing facility & $69(14.6)$ & $68(16.3)$ & $99(23.7)$ & $89(21.3)$ & $101(24.2)$ \\
\hline Privacy maintained at all times of care & $20(4.8)$ & $27(6.5)$ & $93(22.2)$ & $106(25.4)$ & $172(41.1)$ \\
\hline Peaceful wards at night & $23(5.5)$ & $30(7.2)$ & $84(20.1)$ & $120(28.7)$ & $151(38.5)$ \\
\hline
\end{tabular}

\subsection{Patient centeredness related satisfaction}

Concerning patient-centeredness variables, the majority of the respondents $284(68.0 \%)$ were satisfied by communication with the physician and by the number of time nurses and doctors spent with them $300(72.3 \%)$ respondents were satisfied.

\subsection{Service timeliness related satisfaction}

Regarding service timeliness variables, efficient services provided, service layout like a laboratory, pharmacy, and admission procedures were satisfied (74.0\%), (73.4\%), and (69.9\%) respectively.

\subsection{Overall satisfaction level}

Among the respondents $59.1 \%$ (95\% CI: $54.1 \%, 63.6 \%)$ patients were satisfied

\subsection{Multivariate linear regression analysis}

Patients who were a housewife in occupation had 0.244 unit's lower satisfaction than those who were a farmer. Patients who were government employees in occupation had 0.209 units lower by satisfaction than those who were a farmer. Regarding educational status, patients who were primary school had 0.254 unit's lower satisfaction level than those who were illiterate. Regarding residence, patients who were urban residence had 0.160 unit's lower satisfaction than those who were a rural residence. Patients who had the previous admission had 0.237 units greater satisfaction than those who were no previous admission history. Patients who were male had 0.159 units lower satisfaction than female. It can be seen in Table 3.

Table 3. Multivariate linear regression analysis predictors of overall patient satisfaction score

\begin{tabular}{|c|c|c|c|c|c|c|c|c|c|}
\hline \multirow[t]{2}{*}{ Variables } & \multirow[t]{2}{*}{ Category } & \multicolumn{2}{|c|}{$\begin{array}{l}\text { Unstandardized } \\
\text { coefficients }\end{array}$} & \multirow[t]{2}{*}{$\mathrm{T}$} & \multirow{2}{*}{$\begin{array}{c}\mathrm{p}- \\
\text { value }\end{array}$} & \multicolumn{2}{|c|}{$95 \% \mathrm{CI}$} & \multicolumn{2}{|c|}{ Collinearity statistics } \\
\hline & & B & Std. Error & & & LB & UB & Tolerance & VIF \\
\hline \multirow{4}{*}{ Sex } & (Constant) & 4.148 & .162 & 25.626 & .000 & 3.830 & 4.466 & & \\
\hline & Female(ref) & & & & & & & & \\
\hline & Male & -.159 & .089 & -1.778 & .034 & -.335 & .017 & .686 & 1.459 \\
\hline & Illiterate(ref) & & & & & & & & \\
\hline \multirow{3}{*}{$\begin{array}{c}\text { Educational } \\
\text { status }\end{array}$} & Primary & -.254 & .101 & -2.510 & .012 & -.453 & -.055 & .625 & 1.601 \\
\hline & Secondary & -.285 & .120 & -2.366 & .018 & -.521 & -.048 & .587 & 1.705 \\
\hline & Tertiary & -.224 & .135 & -1.665 & .097 & -.488 & .040 & .401 & 2.493 \\
\hline \multirow{3}{*}{ Residence } & Rural(ref) & & & & & & & & \\
\hline & Urban & -.160 & .088 & -1.819 & .040 & -.332 & .013 & .663 & 1.508 \\
\hline & Farmer(ref) & & & & & & & & \\
\hline \multirow{2}{*}{ Occupation } & Housewife & -.244 & .098 & -2.493 & .013 & -.436 & -.051 & .632 & 1.583 \\
\hline & Governmental employee & -.209 & .120 & -1.741 & .034 & -.445 & .027 & .627 & 1.595 \\
\hline Admission & Medical (ref) & & & & & & & & \\
\hline Ward & Surgical & .267 & .136 & 1.964 & .050 & .000 & .535 & .947 & 1.056 \\
\hline Previous & No(ref) & & & & & & & & \\
\hline admission & Yes & .237 & .076 & 3.132 & .002 & .088 & .387 & .897 & 1.115 \\
\hline
\end{tabular}

This study clearly showed the magnitude of overall patient satisfaction with inpatient service was $59.1 \%$ (95\% CI: 54.1\%, 63.6\%). The study done at Debre Markos Hospital of Ethiopia which was $56.0 \%$ [22]. The difference might be due to the availability of different specialist professionals, 
the availability of service. $58.13 \%$ of the respondents were satisfied with cleanness of the ward, a study in Tanzania $88.5 \%$ were satisfied with cleanness of the ward [33]. 61.2\% of the patients were also satisfied with the hygiene of the bed and a study in Tanzania were $72.8 \%$ [33]. This difference may be due to hospital organizational structure and hygienic practice.

In this study, the finding showed that patients who were male had 0.159 unit's lower satisfaction than females $(B=-0.159$, (95\%CI: $-0.335,-0.017)$ ). The study was done in China teaching hospital males more likely satisfied than females [34]. The possible explanation in Ethiopia, female such as pregnant got health care exempted service. For this reason the satisfaction level greater when compared to males. The result of this study revealed that patients who were urban residence had 0.160 units lower satisfaction than those who were rural residence $(\mathrm{B}=-0.160,(95 \% \mathrm{CI}:-.332,-.013))$. Evidence shows that rural residents are more satisfied than urban residents a study conducted at Debre Markos Hospital [22]. This may be due to private hospital availability in the urban area.

Regarding educational status, patients who were primary school had 0.254 unit's lower satisfaction level than those who were illiterate $(B=-0.254$, (95\%CI:-.453, -.055)). Similarly; the study conducted at Jimma University specialized hospital also indicated a significant association of the satisfaction with the educational level of the respondents [4]. In this study, patients who had a previous admission 0.237 unit's greater satisfaction $(\mathrm{B}=0.237$, $(95 \% \mathrm{CI}$ : $0.088,0.387))$. But, the study in Jimma University Specialized Hospital participants who did not have the previous admission was more likely satisfied [4].

\section{CONCLUSION}

The level of patient satisfaction was low, it was 59.1\% (95\%CI: 54.1\%, 63.6\%). Sex of patients, residence, previous admission, educational status, and occupational status was associated with patients satisfaction.

\section{REFERENCES}

[1] Belayneh, M., "Inpatient satisfaction and associated factors towards nursing care at Felegehiwot referral Hospital, Amhara regional state, Northwest Ethiopia," Global journal of medicine and public health,. vol. 5, no. 3, 2016.

[2] Donabedian, A., "An introduction to quality assurance in health care", Oxford University Press, 2003.

[3] Takele, et al., "Determinants of patient satisfaction with outpatient health services at public and private hospitals in Addis Ababa, Ethiopia," Afr J Prm Health Care Fam Med., vol. 4. no. 1, pp. 384, 2012.

[4] Assefa F, Mosse A., "Assessment of clients' satisfaction with health service deliveries at Jimma University specialized hospital," Ethiopian Journal of Health Sciences, vol. 21, no. 2, pp. 101-109, 2011.

[5] Stewart MA., "Effective physician-patient communication and health outcomes: a review," Can Med Assoc J., vol. 152, no. 9, pp. 1423-1433, 1995.

[6] Qadri SS, et all., "An assessment of patients satisfaction with services obtained from a tertiary care hospital in rural Haryana," International Journal of Collaborative Research on Internal Medicine \& Public Health, vol. 4, no. 8, pp. 1524-1537, 2012.

[7] Yilmaz M., "Patient satisfaction: A Criteria of Health Care Quality," The Cumhuriyet Nursing Journal, vol. 5, no. 2, pp. 69-74, 2001.

[8] Bayin, G., Önder, R Ö., "A Research for Determining The Patient Loyalty Level of Outpatients Who Admitted To A University and A Training And Research Hospital In Ankara," Hacettepe Journal of Health Administration, vol. 16, no. 2, pp. 105-121, 2013.

[9] Avis M, Bond, M, Arthur, A A., "Satisfying solutions? a review of some unresolved Issues in the Measuring of Patient satisfaction," Journal of Advanced Nursing, vol. 22, no. 2, pp. 316-322, 1995.

[10] Liu YW, G., "Inpatient satisfaction with nursing care, and factors influencing satisfaction in a teaching hospital in China," Journal of Nursing Care Quality, vol. 22, no. 3, pp. 266-271, 2007.

[11] Dzomeku V.M., et al., "in-patient satisfaction with nursing care: a case study at kwame nkrumah university of science and technology hospital," International Journal of Research in Medical and Health Sciences, vol. 2, no. 1, pp. 18-24, 2013.

[12] Palese A, TM, et al., "Surgical patient satisfaction as an outcome of nurses' caring behaviors: a descriptive and correlational study in six European countries," J. Nurs. Scholarsh., vol. 43, no. 4, pp. 341-350, 2011.

[13] Gani N, et al., "Assessment of patient satisfaction with mental health services in a tertiary care setting," J. Ayub. Med. Coll. Abbottabad, vol. 23, no. 1, pp. 43-46, 2011.

[14] Molla M, et al., "Assessment of adult patients satisfaction and associated factors with nursing care in Black Lion Hospital, Ethiopia; institutional-based cross-sectional study, 2012," International Journal of Nursing and Midwifery, vol. 4, no .6, pp. 49-57, 2014.

Int. J. Public Health Sci, Vol. 9, No. 2, June 2020: 76 - 81 
[15] Booyens, SW., "Introduction to health service management 2nd Ed," Lansdowne Cape Town Juta, 2004.

[16] Hamilton M., Essat Z., "Minority ethnic users' experiences and expectations of nursing care," Journal of Research in Nursing, vol. 13, pp.1 02-110, 2008.

[17] Chaka B., "Adult patient satisfaction with nursing care, MPH thesis, department of community health," Addis Ababa University, 2005.

[18] Oljira L., Gebre-Selassie, S., "Satisfaction with outpatient health services at Jimma hospital, South West Ethiopia," Ethiopian Journal of Health Development, vol. 15, no. 3, pp. 179-184, 2001.

[19] Newman R D., et al., "Satisfaction with outpatient health care services in Manica Province, Mozambique," Health Policy and Planning, vol. 13, no. 2, pp. 174-180. 1998.

[20] Dagnew M, Zakus, D., "Community perception on OPD performance of a teaching hospital in Gondar town," Ethiopian Medical Journal, vol. 35, no. 3, pp. 153-160, 1997.

[21] Girmay, A., "Assessment of clients' satisfaction with outpatient services in Tigray Zonal Hospitals," Addis Ababa, 2006.

[22] Alemu S., et al., "Changes in inpatient satisfaction with nursing care and communication at Debre Markos Hospital, Amhara Region, Ethiopia," American Journal of Health Research, vol. 2, no. 4, pp. 171-176, 2014.

[23] A. A. Mona, et al., "Determinants of patient satisfaction at tertiary care centers in Lebanon," Open Journal of Nursing, vol. 4, no. 13, pp. 939-946, 2014.

[24] Elias N, S. Accorsi, Eds., "Federal Democratic Republic of Ethiopia, Policy and Practice Information for Action," Federal Ministry of Health, Addis Ababa, Ethiopia, 2014.

[25] Ministry of Health Federal Democratic Republic of Ethiopia, Health Sector Development Programme IV 2010/2011-2014/2015. Ministry of Health, Addis Ababa, Ethiopia, pp. 4-114, 2011.

[26] FMOH, "Medical Services Directorate Ethiopian Hospital Management Initiative Hospital Performance Monitoring and Improvement Manual," July, 2011.

[27] Bankauskaite VS, O., "Why are people dissatisfied with medical care services in Lithuania? A qualitative study using responses to open-ended questions," International Journal for Quality in Health Care, vol. 15, no. 1, pp. 23-29, 2003

[28] Westaway MS., et al., "Interpersonal and Organizational Dimensions of Patient satisfaction: The Moderating Effects of Health Status," International Journal for Quality Health Care, vol. 15, no. 4, pp. 337-344, 2003.

[29] WHO., "Working Together for Health. Geneva," WHO publications: The World Health Report, 2006.

[30] Aldaqal SM., et al., "Determinants of Patient Satisfaction in the Surgical ward at a University Hospital in Saudi Arabia," Life Science Journal, vol. 9, no. 1, pp. 277-280, 2011.

[31] Ghose S, SV. A., "Patient satisfaction with medical services: A hospital-based study," Health and PopulationPerspectives and Issues, vol. 34, no. 4, pp. 232-242, 2011.

[32] Okafoagu N., et al., "Clients satisfaction with anti retroviral therapy services in a tertiary hospital in Sokoto, Nigeria," Journal of AIDS and HIV Research, vol. 5, no. 9, pp. 328-333, 2013.

[33] Muhondwa E., et al., "Patient satisfaction at the Muhimbili national hospital in Dar Es Salaam," Tanzania. East Afr J Public Health, vol. 5, no .2, pp. 67-73, 2008.

[34] Chen H., et al., "Factors influencing inpatients' satisfaction with hospitalization service in public hospitals in Shanghai, People's Republic of China," Patient preference and adherence, vol. 10, pp. 469-477, 2016. 